; DOE/EI/22622--TI TI DE92 007400

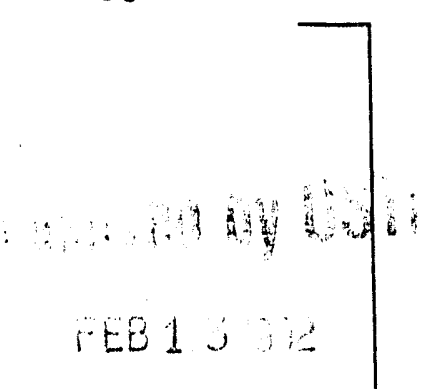

FINAL REPORT

STATE HEATING OIL \& PROPANE PRICE (SHOPP) SURVEY 1990 -1991 Heating Season

The Pennsylvania Energy Office

Bureau of Fossil Fuels

July 1, 1991

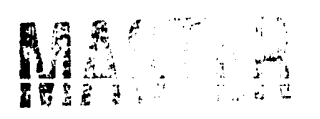




\section{STATE HEATING OIL \& PROPANE PRICE (SHOPP) SURVEY}

\section{INTRODUCTION}

The State Heating Oil and Propane Price (SHOPP) survey for the 1990-1991 heating season was conducted by the Pennsylvania Energy Office (PEO) in conjunction with the U.S. Department of Energy, Energy Information Administration (DOE/EIA). The objective of the program was to collect price information for No. 2 heating oil and propane. Prices were to be collected on the first and third Mondays of each month, starting on October 1, 1990 and extending through March 18, 1991.

For each heating oil distributor, the PEO was asked to collect charge prices for a standard delivery quantity of No. 2 heating oil.

This year was the first for which information on propane was being sought.

Consequently, there was a desire to establish some baseline data. In addition to price information, the PEO was asked to collect information on the volume of propane distributed by individual dealers for a one-year period starting in September 1989 and ending in August 1990.

For propane prices, the decision for the standard vas a compromise arrived at after several discussions with representatives of the Pennsylvania Propane Gas Association. These discussions indicated that there was a wide variety of market conditions that could not be realistically described with one price. It was agreed that representative prices would be sought for a residence expected to use between one thousand and fifteen hundred gallons during the heating season. 
The PEO agreed to forward the survey results to the DOE/EIA within three days of the date of each survey. DOE/EIA's responsibility was to compile the data from all states and distribute a semi-monthly report. In addition, DOE/EIA undertook responsibility for the collection of primary stock information for No. 2 heating oil.

\section{PREPARATIONS FOR SURVEY}

The DOE/EIA assumed responsibility for the methodology used to develop the sample size and to select companies. Companies who distribute home heating oil or propane to residential customers in Pennsylvania were candidates for inclusion. The ElA sent a letter to each company selected notifying it of its inclusion in the survey. The names of the companies selected to participate in the survey were provided to the PEO. Contact information was also provided.

The DOE/EIA provided forms for recording the data and transmitting it via FAX machine. Because of a shortage of computer equipment, the PEO deferred installation of the PEDRO program which was designed to facilitate data collection and reporting. The PEO expects that PEDRO will be installed for PEO use prior to the inception of the 1991-92 survey.

\section{THE SURVEY}

The survey phone calls were made on the first and third Mondays of the months of October 1990 through March 1991. Prices of No. 2 heating oil were obtained from thirty-two (32) dealers. In the case of propane, nineteen (19) dealers were contacted. 
Many of the companies on the list of propane dealers first provided to the PEO turned out not to be residential heating distributors. In addition, several of the heating oil dealers were located outside of Pennsylvania and had not received their contact letters from the DOE/EIA by the time the survey started. Most of the start up problems were resolved by the middle of November. The survey prices collected on survey dates were generally faxed to the DOE/EIA by mid-week.

\section{RESULTS}

The results that are presented in Table 1 and Figures 1 and 2 are unweighted averages. Consequently, they may be different from the summary results reported by DOE/EIA.

\section{No. 2 Fuel Oil}

When the survey started on October 1,1990 , the No. 2 charge price average for residential customers wds 123.1 cents per gallon. The high of 128.5 cents for the season was reached two weeks later on October 15 . The price dropped gradually to 117.5 cents on January 7,1991 , but rose again to 120.5 cents on January 21 before beginning a steady decline to end at 102.0 cents on March 18.

\section{Propane}

The 1990 - 1991 heating season was the first for which propane prices were included in the residential price survey. The results of the October 1, 1990 price survey indicated an average unweighted price of 127.4 cents per gallon for a residential customer. The unweighted average price reached its peak two weeks later on October 15 at 131.0 cents per 
State Heating Oil and Propane Price Survey

Page 4

gallon, a rise of 3.7 cents. From that point, the overall trend was downward. Prices ended at

115.3 cents on March 13, seven percent below its peak for the season attained on October 15. 
TABLE 1

STATE HEATING OIL \& PROPANE SURVEY (SHOPP)

(cents per gallon)

\begin{tabular}{|c|c|c|}
\hline Date & No. 2 Heating On & Propano \\
\hline 01-Oct-90 & 123.1 & 127.4 \\
\hline $15-$ Oct-90 & 128.5 & 131.0 \\
\hline 05-Nov-90 & 126.1 & 124.0 \\
\hline 19-Nov-90 & 125.2 & 126.0 \\
\hline 03-Dec-90 & 124.9 & 126.4 \\
\hline 17-Dec-90 & 120.9 & 119.3 \\
\hline 07-Jan-91 & 117.5 & 124.2 \\
\hline 21-Jan-91 & 120.5 & 124.6 \\
\hline 04-Feb-91 & 115.3 & 122.3 \\
\hline 18-Feb-91 & 111.5 & 117.6 \\
\hline 04-Mar-91 & 106.1 & 116.3 \\
\hline 18-Mar-91 & 102.0 & 115.3 \\
\hline
\end{tabular}




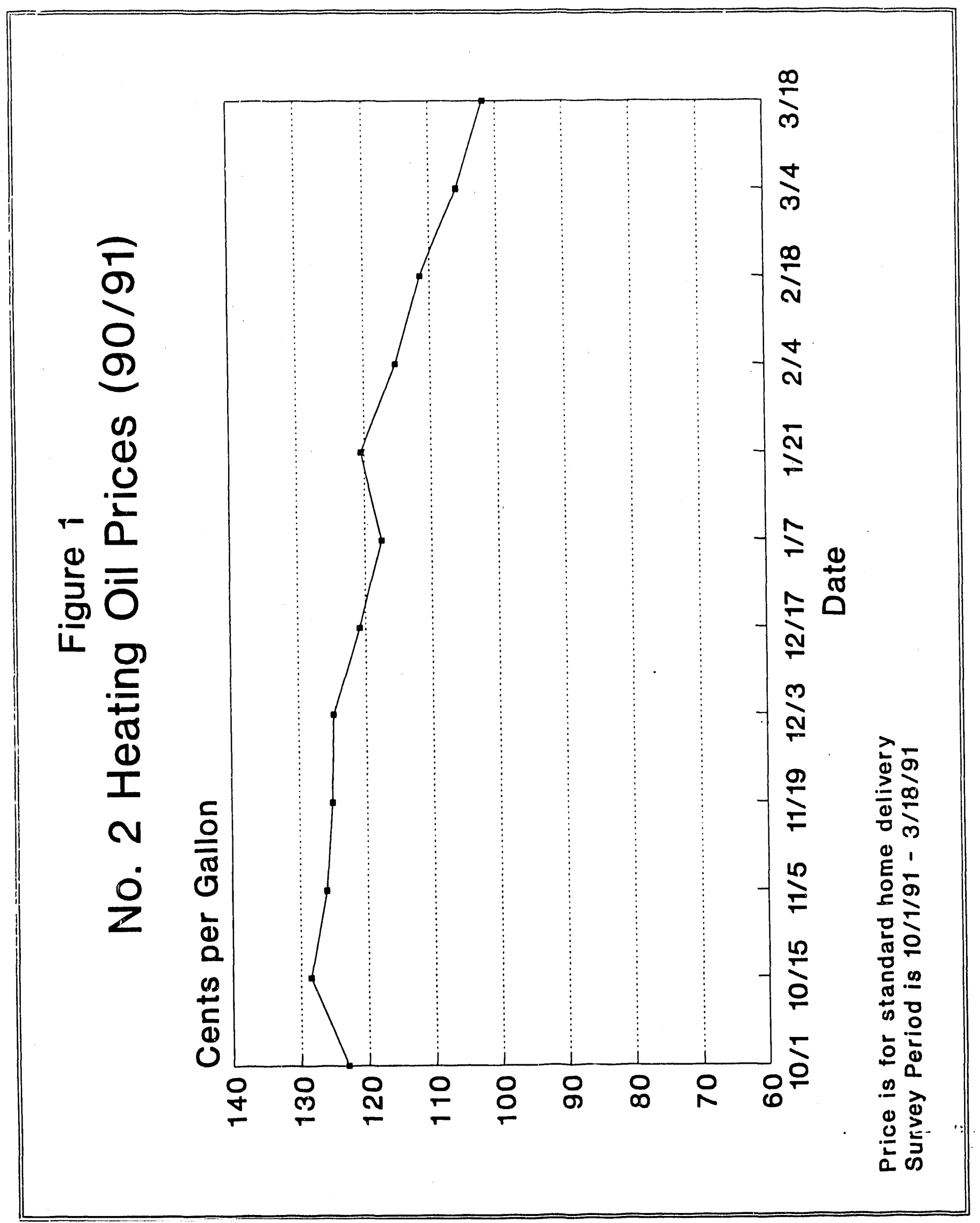




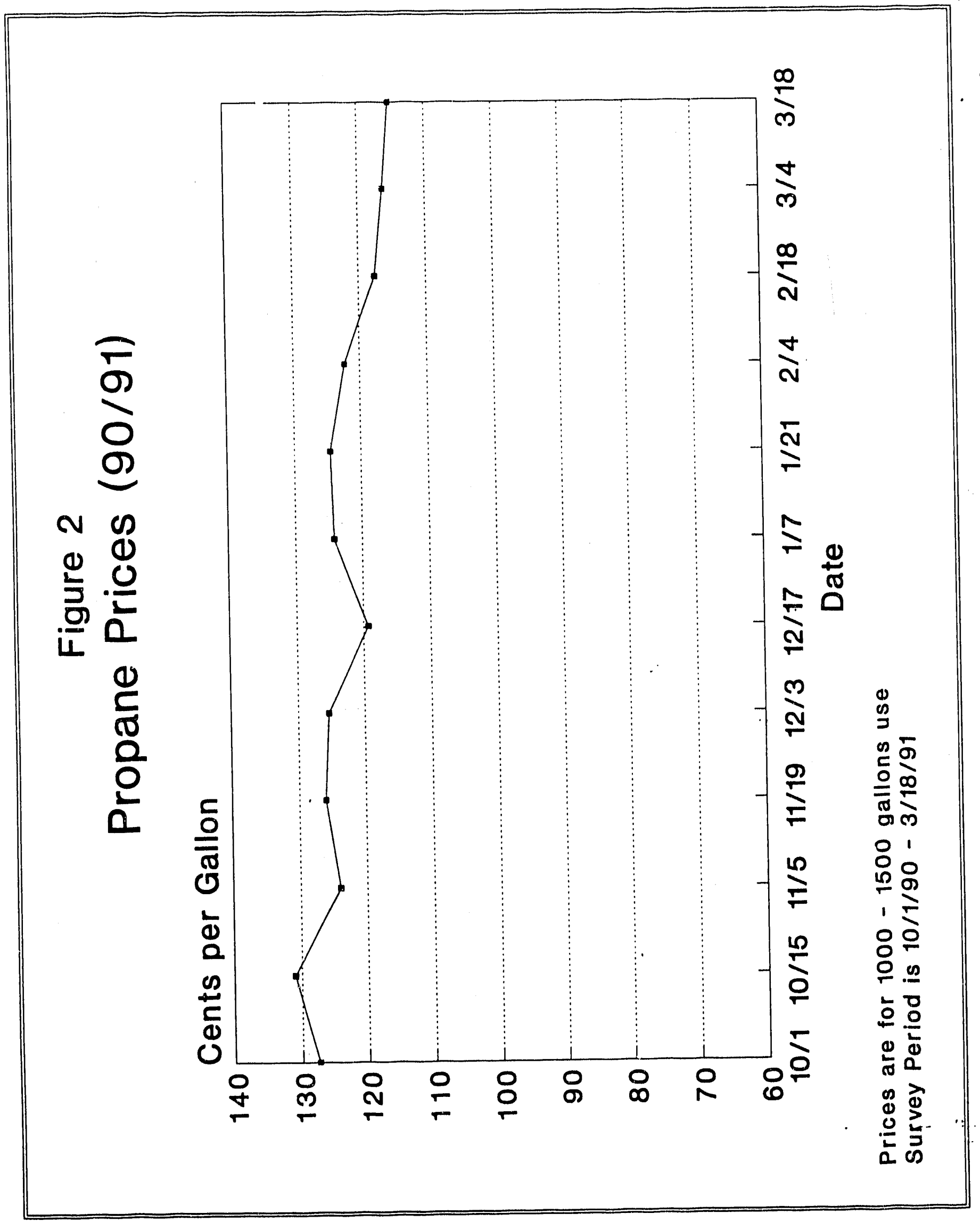



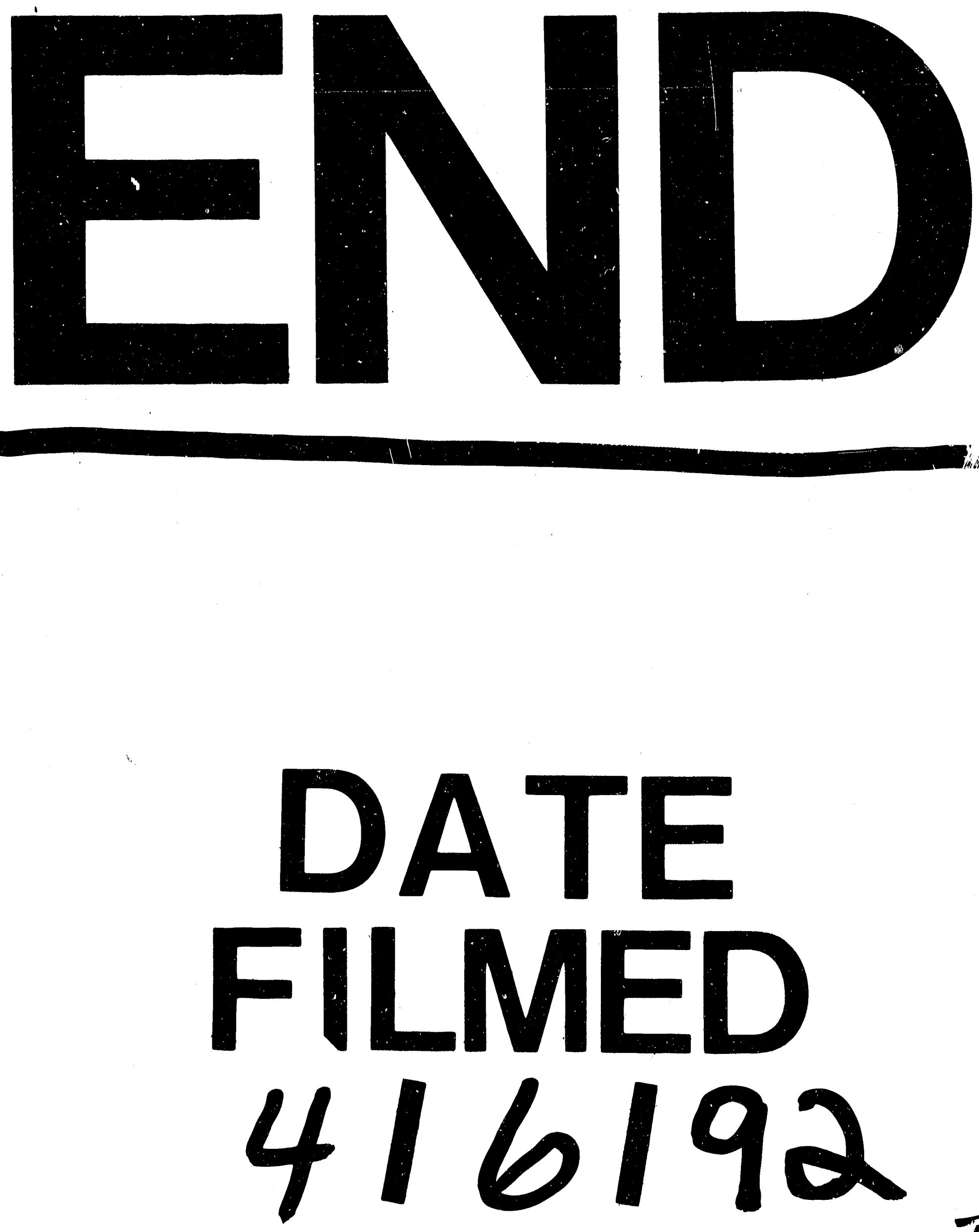

1

$I$ 


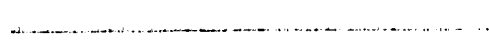

